\title{
Integral solution for oil spill detection using SAR data
}

\author{
Olga Nickolaevna Gershenzon \\ Vladimir Eugenyevich Gershenzon \\ Sergey Vladimirovich Osheyko \\ RDC ScanEx, info@scanex.ru
}

\begin{abstract}
Oil spills cause huge material damage. Oil and oil products spills may occur at any stage of the offshore oil production and transportation cycle. Therefore taking into account the current trends of oil production, the system developing for shelf and tank fleet monitoring becomes very crucial today.

This paper describes the technology being implemented to improve oil spill monitoring and surveillance, to ensure SAR data acquisition and processing and to develop geographic information systems in support of spill response decision making. The results of technology implementation are also presented below.
\end{abstract}

Keywords: Fast Oil Spill Detection, Oil Slicks, Remote Sensing, Radar, Monitoring

\section{INTRODUCTION}

Oil spills in the marine environment can have wide spread impact and long-term consequences on wildlife, fisheries, coastal and marine habitats, human health and livelihood, as well as recreational resources of coastal communities. Annually, fuels constitute $48 \%$ of the oil pollutions in the oceans and crude oil - 29\%. Tanker accidents make up only $5 \%$ of all pollution entering into the sea (Fingas, 2001).

Oil spill detection on sea surface is a very difficult and actual task. Satellite detection is well adapted since it regularly produces images in difficult access areas (Hühnerfuss et al., 1983). They allow instantaneous coverage of areas as wide as $500 \times 500 \mathrm{~km}^{2}$. SAR is useful particularly for searching large areas and observing oceans at night and under cloudy weather conditions. Usually even small volumes of oil cover large areas (several hundred meters) and thus the need for very high spatial resolution in SAR images is not crucial.

Since the launch of the first SAR sensor, many cases of oil spill detection have been documented using SAR on board the RADARSAT-1, Envisat-1 and other satellites (Bern et al, 1992; Masuko et al., 1995; Gade et al., 1998; Ivanov, 2000). It was shown that SAR due to its resolution allowed for detection, localization and furnishing the information on the dimensions, structure and drift of the oil spills.

From this viewpoint it is important to create an optimal for consumer oil spill monitoring technology based on satellite data.

\section{OIL SPILL DETECTION TECHNOLOGY}

\subsection{Oil spill detection cycle}

Usually the oil spill detection cycle can be divided into 7 steps (fig. 1):

a. At the first, person concerned with the monitoring of the interested region have to plan and order satellite data through an operator.

b. Earth observation satellite acquires images of the area of interest: coastal zones, open sea etc. Today, RADARSAT-1 and Envisat-1 are the two main providers of satellite SAR images for oil spill monitoring. They can observe the area of interest every day. 
c. The next step is receiving satellite data by ground receiving station. Ground receiving stations regularly receive data (particularly SAR data) from various satellites so as to provide data over selected areas.

d. Pre-processing of radar remote sensed data, including image cutting, georeferencing and calibration. It can be performed using corresponding software. This step is the most time critical.

e. The next step is the main part of the all oil spill monitoring circle - the oil spill detection using SAR and other RS data and geographic information systems (GIS). This part is carried out by experienced experts applying sophisticated algorithms to find oil slicks.

A study of the best practice of manual versus automatic oil spill systems revealed that operators show some variance in detecting spills, particularly in assigning an oil spill confidence estimate. An automatic algorithm with a reliable and objective oil spill confidence estimate would be highly desirable. The need for automatic algorithms depends on the number of images to be analyzed, but for monitoring large ocean areas and coastal zones it is a cost-effective alternative to manual inspection (Brekke, Solberg, 2005).

f. The next step of oil spill detection cycle is drawing up an oil detection report. It contains the GIS information about probability of oil spill presence in the area of interest.

g. The last step of the cycle is to make the end user aware of current status for the decision making.

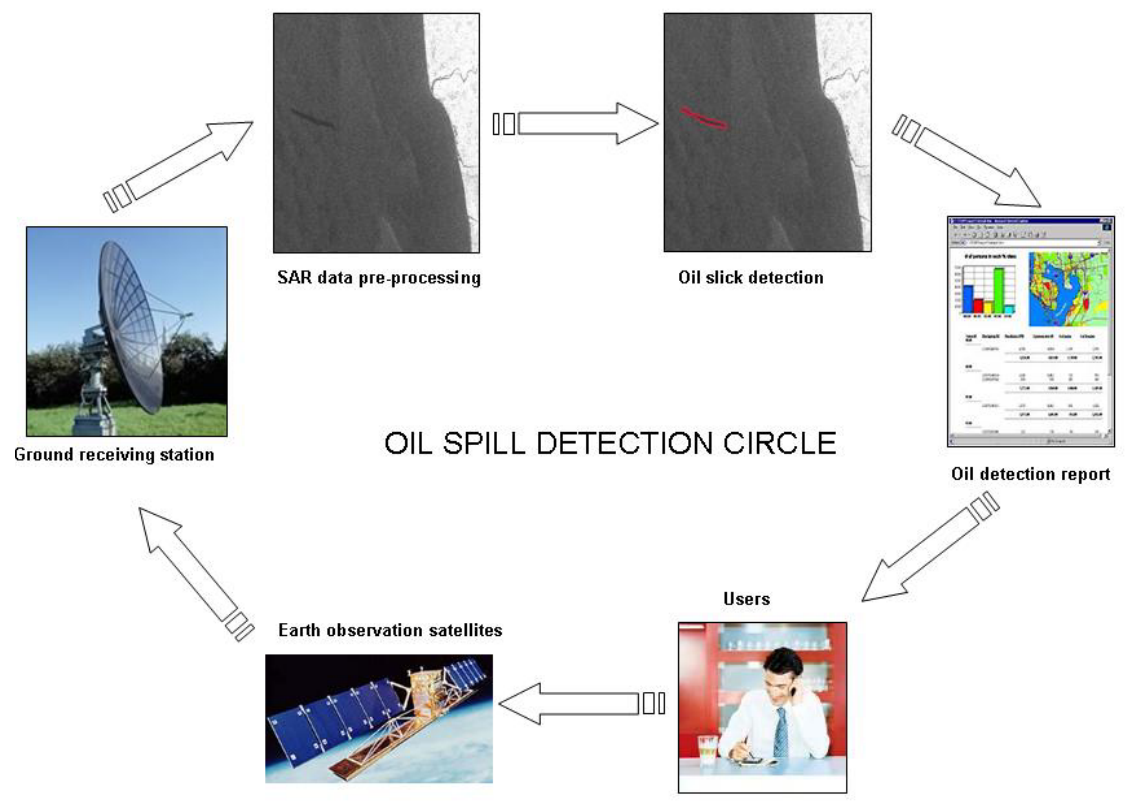

Figure 1. Oil spill detection cycle

All stages of the above described cycle are accompanied by experienced technologists and experts.

Real-time data processing assumes vital importance when solving the task of fast radar data processing for oil spill detection. 


\subsection{Integral solution for oil spill monitoring}

The R\&D Center ScanEx has developed an integral solution for the SAR data acquisition, processing and oil spill monitoring. This technology has combined the multi-mission UniScan $^{\mathrm{TM}}$ ground station, the ScanEx SAR Processor ${ }^{\circledR}$ and ScanEx Image Processor ${ }^{\circledR}$ software applications.

Ate present the UniScan ${ }^{\mathrm{TM}}$ station is capable to receive data from the 12 operating Earth observation satellites including the RADARSAT-1 and Envisat-1 (table 1). UniScan ${ }^{\mathrm{TM}}$ station $^{-}$ is designed for the reception and processing of images transmitted from low-orbiting Earth satellites in X-band with data rates up to $170 \mathrm{Mbps}$ in one channel. Such data rate allows for transmitting detailed images with the spatial resolution better than one meter (table 1). One UniScan ${ }^{\mathrm{TM}}$ station covers area of about 12 million sq. $\mathrm{km}$. This provides for the most efficient routine monitoring of the coverage zone without leaving the place of work. In addition, the expenses for in-situ and aerial observations could be significantly reduced. The UniScan ${ }^{\mathrm{TM}}$ station is not only the tool for data acquisition but also a set of software products for this data storage, processing and thematic analysis.

Table 1. Satellite sensors accessible with UniScan multi-mission station

\begin{tabular}{|c|c|c|c|c|c|}
\hline Sensor & Satellite & $\begin{array}{l}\text { Total number of } \\
\text { spectral bands }\end{array}$ & \begin{tabular}{|c|} 
Spatial \\
resolution, \\
m
\end{tabular} & \begin{tabular}{|l} 
Swath \\
width,km
\end{tabular} & $\begin{array}{c}\text { Revisit } \\
\text { period(for one } \\
\text { satellite at } \\
\text { middle } \\
\text { latitudes) } \\
\end{array}$ \\
\hline MODIS & $\begin{array}{l}\text { Terra } \\
\text { Aqua }\end{array}$ & $\begin{array}{l}36 \text { (visible, } \\
\text { IR) }\end{array}$ & $\begin{array}{c}250,500 \\
1000\end{array}$ & 2300 & $1-2$ times a day \\
\hline PAN & EROS A & 1 (visible) & 2.0 & 13.5 & 3-4 days \\
\hline PAN & EROS B & 1 (visible) & 0.7 & 7.0 & 2.8 days \\
\hline $\begin{array}{l}\text { HRVIR } \\
\text { MONO }\end{array}$ & SPOT 4 & 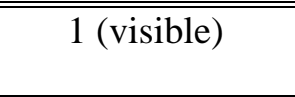 & 10 & 60 & 1-4 days \\
\hline $\begin{array}{l}\text { HRVIR } \\
\text { XS }\end{array}$ & SPOT 4 & $\begin{array}{l}4 \text { (visible, NIR, } \\
\text { SWIR) }\end{array}$ & 20 & 60 & 1-4 days \\
\hline PAN & IRS-P5 & 1 (visible) & 2.5 & 30 & 5 days \\
\hline LISS-3 & IRS-P6 & $\begin{array}{c}4 \text { (visible, NIR, } \\
\text { SWIR) }\end{array}$ & 23 & 140 & 24 days \\
\hline AWiFS & IRS-P6 & $\begin{array}{c}4 \text { (visible, NIR, } \\
\text { SWIR) } \\
\end{array}$ & 55 & 740 & 5 days \\
\hline $\begin{array}{c}\text { LISS-4 } \\
\text { Mono }\end{array}$ & IRS-P6 & "1 (visible red) & 5.8 & 70 & 5 days \\
\hline $\begin{array}{c}\text { LISS-4 } \\
\text { MX }\end{array}$ & IRS-P6 & 3 (visible, NIR) & 5.8 & 23 & 5 days \\
\hline $\mathrm{TM}$ & Landsat 5 & $\begin{array}{l}\text { (visible, NIR, } \\
\text { SWIR, TIR) }\end{array}$ & 30,120 & 185 & $8-16$ days \\
\hline SAR & RADARSAT-1 & $\begin{array}{c}\text { 1(microwave, C- } \\
\text { band, } 5.6 \mathrm{~cm} \text { ) }\end{array}$ & $8 \ldots 100$ & $50 \ldots 500$ & $\begin{array}{c}\text { from daily to } 6 \\
\text { days* }\end{array}$ \\
\hline ASAR & $\overline{\text { ENVISAT }}$ & $\begin{array}{c}\text { 1(microwave, C- } \\
\text { band) }\end{array}$ & $30 \ldots 150$ & $100 \ldots 405$ & 35 day repeat \\
\hline
\end{tabular}

* Depending on the imaging mode (combination of spatial resolution and swath width). 
ScanEx SAR Processor ${ }^{\circledR}$ (SSARP) software has been developed for processing data from the Canadian RADARSAT-1 spaceborne synthetic aperture radar (SAR). ScanEx SAR Processor ${ }^{\circledR}$ is used at several certified stations of the RADARSAT receiving network and is fully compliant with the international standards on the synthesized image quality, processing algorithms used and output format structure. RDC ScanEx eternally presses towards to optimize this process. Synthesis takes 5-15 minutes per one scene of RADARSAT Standard mode using SAR Processor software. Synthesis time for ScanSAR mode scene equals to 1-2 hour. It's expected that the synthesis time will be reduced to 10-15 minutes per one scene of RADARSAT ScanSAR scene by the end of year 2006 (today synthesis time for a ScanSAR mode scene amounts to 1 hour on average).

Synthesized radar data are then processed using ScanEx Image Processor ${ }^{\circledR}$ in order to find oil spillages. ScanEx Image Processor ${ }^{\circledR}$ Microsoft ${ }^{\circledR}$ Windows ${ }^{\circledR}$-based application is designed to process the Earth observing satellite and aerial photo survey data. The program tools package enables to resolve a wide range of tasks: from preliminary images processing to thematic analysis and getting final thematic products.

The program consists of the basic configuration and add-on modules, such as:

- 3D modeling and visualization;

- terrain analysis;

- radar images thematic processing;

- hydrological modeling;

- software development kit (SDK).

The latest version 2.5 of the ScanEx Image Processor ${ }^{\circledR}$ supports automatic and manual oil spill detection and other functions for radar data processing, such as:

- radar images segmentation using specific algorithms;

- possibility to account for images texture properties;

- results thematic calibration using references;

- generation of thematic raster maps;

- automatic vectorization;

- possibility to get statistic probability of assessing the pixel as oil spill;

- possibility of automatic vectorization of processed data.

- ship detection.

These features allow for fast and precise detection of an oil spillage on radar data in the shortest possible time, up to 5 minutes per one scene with coverage area of $100 * 100 \mathrm{~km}^{2}$.

\section{RESULTS OF TECHNOLOGY IMPLEMENTATION}

In May 2006 the ScanEx SAR integral technology was successfully tested to detect oil spills in the Caspian Sea.

Experts of the RDC ScanEx analyzed of RADARSAT-1 archived data and have ordered the acquisition of new images.

According to RADARSAT-1 images dated 3.4.2006 in the same area of the Caspian Sea the big oil spillage really was revealed. In the new image received on 24.4.2006 by UniScan ${ }^{\mathrm{TM}}$ station, the new oil spillage covering the area of about $46 \mathrm{~km}^{2}$ is distinctly decoded. Two images comparison results with due account for weather conditions have allowed defining approximate coordinates of the source of oil gushing forth. 
On the resulting image (figure 2) two RADARSAT-1 images are combined:

- yellow color allocates the oil spillage which has been found out in the picture of 3.4.2006;

- dark blue color allocates the oil spillage which has been found out in the picture of 24.4.2006;

- the red circle in the center notes a source of gushing forth oil;

- bright points - oil-extracting platforms and vessels.

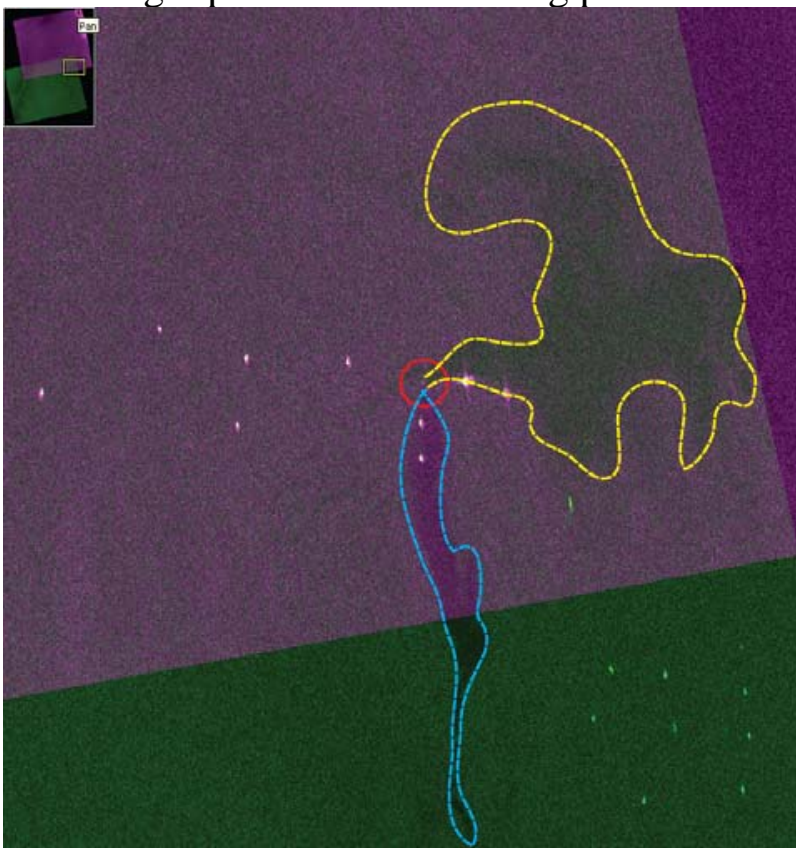

Figure 2 Oil spill in the Caspian Sea

(C)MDA, CSA, RDC ScanEx, 2006

By experts' estimations, the source of oil emissions was the old conserved well that has activated under the influence of a mud volcano. The mud volcano represents a serious threat to the abandoned offshore oil production platforms because of the danger of polluting the surface with oil spills.

RDC ScanEx experts have expedited the order execution by detecting and delineating the source of oil pollution on the sea surface.

\section{CONCLUSION}

At present, oil spill monitoring task is described in several steps, including receiving of the satellite data, pre-processing and spillage detection.

The integral solution developed by RDC ScanEx allows bringing on-line monitoring in compliance with the European standards due to an increased satellite data processing rate. The interval between processing and spill response decision-making decreases to one hour only!

The technology meets the customer's requirements for fast data processing.

\section{REFERENCES}

Brekke C., Solberg A. H.S., 2005. Oil spill detection by satellite remote sensing. Remote Sensing of Environment vol. 95 pp.1-13. 
Masuko, H., T. Kobayashi, K. Okamoto, and W. Alpers. 1995. Observation of artificial slicks with SIR-C/X-SAR around Japan. Proc. IGARSS'95, Florence, Italy, 14-18 July 1995, pp. 227-229

Ivanov A, A.Yu., 2000. Oil pollution of the sea on Kosmos -1870 and Almaz-1 radar imagery. Earth Observation \& Remote Sensing, 15(6), pp. 949-966

Gade, M., and S. Ufermann., 1998. Using ERS-2 SAR images for routine observation of marine pollution in European coastal waters. Proc. of IGARSS'98, Seattle, USA, July 6-10, 1998

Witte, F., 1986. Oil slick detection with a side looking airborne radar. Proc. of IGARSS'86, Zurich, 8-11 Sept. 1986, pp. 1369-1374 